\title{
Bicaudal-D, a Drosophila gene involved in developmental asymmetry: localized transcript accumulation in ovaries and sequence similarity to myosin heavy chain tail domains
}

\author{
Beat Suter, Laura M. Romberg, and Ruth Steward \\ Department of Biology, Princeton University, Princeton, New Jersey 08544-1003 USA
}

\begin{abstract}
The Bicaudal-D (Bic-D) gene is essential for the differentiation of the oocyte in Drosophila. Dominant gain-offunction mutations result in the formation of double abdomen embryos. The Bic-D gene was cloned and identified using restriction fragment length polymorphisms, Northern analysis, and transformation rescue. Bic-D RNA accumulates in the oocyte during the earliest stages of oogenesis and is localized anteriorly in later stages. The predicted protein contains several extended amphipathic helices, and its similarity to myosin heavy chain tails, paramyosin, and kinesin suggests a similar type of coiled-coil protein interaction.
\end{abstract}

[Key Words: Bicaudal-D; RNA localization; amphipathic helices; myosin]

Received July 31, 1989; revised version accepted September 22, 1989.

The mechanisms that establish anterior-posterior polarity in insect embryos have been investigated since the turn of the century. Posterior organizing activity was discovered in eggs of the dragonfly Platycnemis as early as 1929 (Seidel 1929) and subsequently in several other insect systems using classical embryological approaches (for review, see Sander 1976; Frohnhöfer et al. 1986). Disruption of anterior activity by UV irradiation, pricking, centrifugation, or RNase treatment not only results in the lack of anterior structures in the embryos of the midges Chironomus and Smittia but also in their replacement by posterior structures. The two abdomens are arranged in mirror-image symmetry, and the resulting pattern is referred to as the bicaudal or double abdomen phenotype (Yajima 1960; 1964; Kalthoff and Sander 1968; Schmidt et al. 1975; Kandler-Singer and Kalthoff 1976). In Drosophila, mutations in at least three different maternal-effect loci, bic, Bic-C, or Bic-D, also cause such a double abdomen phenotype (Fig. 1A; Bull 1966; Nüsslein-Volhard 1977; Mohler and Wieschaus 1986). Of these, the three dominant gain-of-function alleles at the BiC-D locus (71.34, IIIE48, and YC67) have the highest penetrance. In addition to the bicaudal phenotype produced by females heterozygous or homozygous for a gain-of-function mutation (at $18^{\circ} \mathrm{C}$ ), eggs laid by homozygous BiC-D females exhibit a cold-sensitive chorion phenotype and females homozygous for a recessive mutation in Bic-D are sterile (Mohler and Wieschaus 1986).

Weak Bic-D dominant phenotypes show a reduction of anterior structure, whereas strong phenotypes lack anterior structures entirely and form posterior structures at the anterior end instead (Fig. 1A). The cellular mechanisms underlying this transformation are not understood. In wild-type embryogenesis, an anterior and a posterior organizing center act together in setting up the anteroposterior polarity (for review, see Nüsslein-Volhard et al. 1987). The anterior organizing activity depends on the bicoid gene product, whereas the posterior activity depends on gene products of the posterior group genes such as oskar and nanos. Associated with the anterior to posterior transformation in embryos from Bic-D mothers is a reduction of bicoid protein and the presence of posterior factors at the anterior pole (Lehmann and Nüsslein-Volhard 1986; Driever and Nüsslein-Volhard 1988b). Temperature shift experiments indicate that the cold-sensitive period of the Bic-D dominant phenotype is during the final $6 \mathrm{hr}$ of oogenesis, about stages 11-14 (Mohler and Wieschaus 1985). During this same period, anterior and posterior organizing activities can be demonstrated in wild-type oocytes (Sander and Lehmann 1988). Therefore, it is possible that the Bic-D product interacts with components of the posterior and/ or anterior organizing centers to set up the initial anterior-posterior polarity in late oogenesis.

The phenotype resulting from the two loss-of-function mutations (PA66 and R26) is quite different from that caused by the dominant alleles and suggests that the $B i c-D$ gene product is initially required at a very early step in oogenesis. Females homozygous mutant for the 


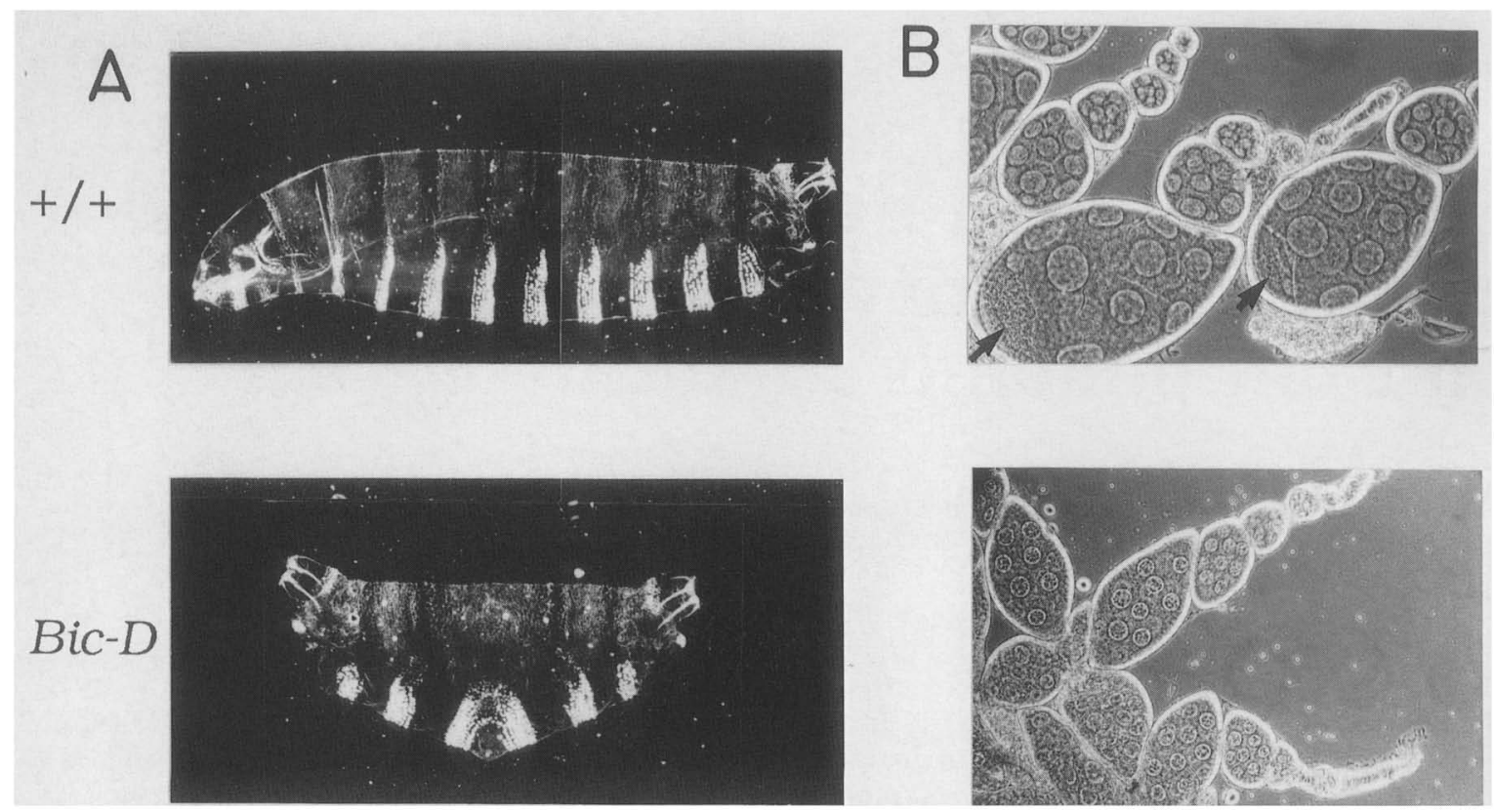

Figure 1. Phenotype of the Bic-D mutants. $(A)$ Effect on embryonic anteroposterior polarity of the dominant maternal-effect mutations of Bic-D (e.g., 71.34, IIIE48, and YC67); (dark-field micrograph). (Top) Wild-type (+1+) embryo (anterior left, dorsal up); (bottom) symmetric Bic-D double abdomen embryo from a Bic-D dominant mutant female (IIIE48/71.34). (B) Effect of the recessive Bic-D mutations (PA66, R26) on oogenesis: In wild-type oogenesis (top), the oocyte develops at the posterior end of the egg chamber (indicated by arrows); in PA66 homozygous females (bottom), the egg chambers contain 16 nurse cells and no oocyte.

two loss-of-function alleles do not lay eggs, and their ovaries are full of partially developed egg chambers. These egg chambers contain no oocytes but have 16 rather than the usual 15 polyploid nurse cells instead (Fig. 1B). The wild-type role of the Bic-D gene product in early oogenesis may be the localization of determinants within the early egg chamber, an essential step for the differentiation of the oocyte at the posterior position. Thus, the role of Bic-D in early egg chamber polarity may be related to the polarity reversal produced at later stages by the dominant gain-of-function alleles.

\section{Results}

\section{Localization of Bic-D}

Previous studies using complementation and recombination analysis localized the Bic-D gene within $D f(2 L) T W 119$ in the cytological region 36C, very close $(<0.022 \mathrm{cM}$ ) and proximal to dorsal (dl) (Steward and Nüsslein-Volhard 1986). We initially attempted to identify the Bic-D gene by determining whether any of the $B i c-D$ mutants were associated with DNA lesions detectable by genomic Southern analysis (Southern 1975) in a $\sim 200-\mathrm{kb}$ region around the $d l$ locus. Because none were found, we decided to map Bic-D with respect to restriction fragment length polymorphisms (RFLPs) in the region. For this purpose, we took advantage of the fact that recombination between a female sterile Bic-D allele and the female sterile $d l$ locus would result in a chromosome that would be fertile over a deficiency that uncovers both genes (Fig. 2A). To be able to map the re- combination site at the molecular level, we used two chromosomes with a high number of restriction site polymorphisms, the dorsal allele $d l^{8}$, induced on a $b p r$ cn wxt bw chromosome, and the Bic-D allele PA66, induced on a $c n b w$ chromosome.

Of 30,000 chromosomes tested, 2 fertile recombinant females were recovered and used to establish the lines rec263 and rec285. Both recombinant females carried the flanking markers $b^{+}$and $p r$, placing the Bic-D gene proximal to $d l$ (map distance between $d l^{8}$ and PA66 is $0.013 \mathrm{cM}$, with $95 \%$ confidence between 0.0036 and $0.034 \mathrm{cM}$; Stevens 1942). This result agrees with the distance obtained in earlier experiments between two other $d l$ and Bic-D alleles (Steward and Nüsslein-Volhard 1986).

Because the recombinant females are fertile, they must have inherited a $d l^{+}$allele from the $P A 66$ chromosome and a Bic- $D^{+}$allele from the $d l^{8}$ chromosome. As shown in Figure 2, B and C, there are two polymorphic HindIII $\left(\mathrm{H}^{\star}, \mathrm{H}^{\star \star}\right)$ sites in the DNA segment immediately proximal to the $d l$ locus. The parental Bic-D chromosome PA66 has these two HindIII sites, whereas they are absent in the parental $\mathrm{dl}^{8}$ chromosome. $\mathrm{H}^{\star}$ is present in rec263 and absent in rec285. $\mathrm{H}^{\star *}$ is absent in both recombinants. Thus, the relative order of markers in this region is Bic- $D^{P A 66}, \mathrm{H}^{\star}, d l^{8}$. The two markers $\mathrm{H}^{\star \star}$ and $B i c-D^{P A 66}$ have not been ordered relative to each other by this recombination mapping.

\section{Transformation rescue of Bic-D Mutants}

The results of the recombination analysis indicated that 
A
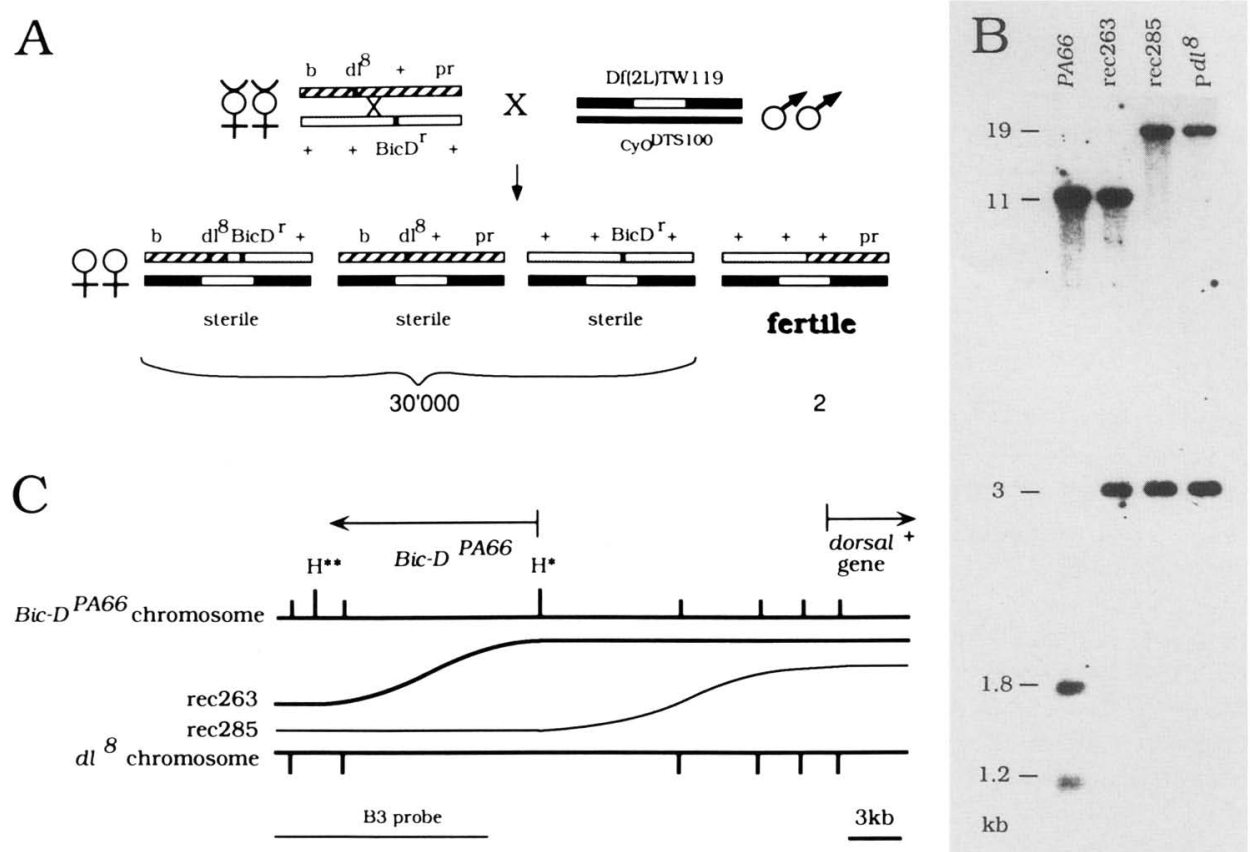

Figure 2. Recombination analysis. (A) Schematic drawing of the strategy used for the isolation of recombinants between $d l$ and $B i c-D$. Only females with a wild-type copy of $d l$ and Bic-D produce viable offspring over the deficiency. A detailed description is given in Methods. Note that the genetic orientation is used (distal left, proximal right) in contrast to the molecular map in $C$ and Fig. 3 . $(B)$ RFLPs in the $d l$ and Bic-D region: a Southern filter of HindIII-digested genomic DNA of the two recombinant lines (rec263 and rec285), their parental Bic-D chromosome $P A 66$, and the parental chromosome of $d l^{8}\left(p d 1^{8:} b\right.$ pr $\left.\mathrm{cn} w \times t b w\right)$. The filter was probed with a recombinant $\lambda$ phage (B3) containing the sequences indicated in $C$. The approximate length of the restriction fragments is indicated. $(C)$ Localization of the recombination sites on the genomic map deduced from the Southern analysis shown in $B$. HindIII sites present in the $d l^{8}$ and the $P A 66$ chromosomes are indicated. $\mathrm{H}^{\star *}$ is only present in the PA66 chromosome; $\mathrm{H}^{\star}$ is in the rec 263 and the $P A 66$ chromosomes. Note that proximal is to the right, and distal is to the left. Recombination occurred to the left of $\mathrm{H}^{\star}$ in recombinant line rec263. Therefore, the Bic- $D^{P A 66}$ lesion maps to the left (proximal) of $\mathrm{H}^{*}$, as indicated by the arrow.

Bic- $D$ is located very close and proximal to $d l$. Our Northern analysis of transcripts encoded by the DNA segment proximal to the $d l$ locus revealed that there are three transcription units in the immediate vicinity of the first polymorphic HindIII site $\left(\mathrm{H}^{\star}\right)$. As shown in Figure $3 \mathrm{~A}$, transcription unit III spans the polymorphic $\mathrm{H}^{\star}$ site, whereas transcription units I and $\mathrm{II}$ are located more proximal. We speculated that one of these transcription units might correspond to the Bic-D gene; to test this possibility, genomic DNA fragments from this region were transformed into flies and assayed for their ability to rescue the female sterility of the recessive loss-of-function Bic-D alleles, PA66 and R26. The three genomic fragments shown in Figure $3 \mathrm{~B}$ were used for transformation. $\mathrm{C}, \mathrm{R}$, and $\mathrm{X}$ were subcloned into the CaSpeR transformation vector, which contains a white ${ }^{+}$ $\left(w^{+}\right)$gene as a marker (Pirrotta 1988).

We found that of $>20$ independent transformants of $C$, none was capable of rescuing the female sterility of the Bic- $D^{-}$alleles. Neither were 20 independent transformants of $\mathrm{R}$ capable of this rescue. Because $\mathrm{R}$ contains transcription units I and II plus an additional $4 \mathrm{~kb}$ of flanking distal sequences that are part of transcription unit III, it seems very unlikely that I or II encodes Bic-D. A quite different result was obtained with fragment $\mathrm{X}$, which encodes the entire transcription units III and II, but only part of transcription unit I. A single copy of the fragment $\mathrm{X}$ rescues the female sterility phenotype of all combinations of the Bic- $D^{-}$alleles. Therefore, the results argue strongly that the DNA encoding transcription unit III is responsible for the rescue of the Bic-D sterility by fragment $\mathrm{X}$. In this context it is interesting to note that in contrast to transcription unit II, transcription unit III encodes an ovarian-specific RNA species (Fig. 3).

\section{Expression of the Bic-D gene}

The Bic-D transcription pattern during development is shown in the Northern blot in Figure 3C. Two transcripts, one of $3.8 \mathrm{~kb}$ and the other of $4.4 \mathrm{~kb}$, are detected in poly $(\mathrm{A})^{+}$RNA prepared from either adult females or dissected ovaries. These Bic-D RNA species are also rather abundant in very early, 0 - to 2 -hr embryos. Because this interval is prior to the onset of high levels of embryonic transcription /which occurs in the 2- to 4-hr interval|, we suspect that these transcripts are of maternal origin and were deposited in the maturing egg during oogenesis (see below). The level of both Bic-D RNA species appears to drop in the 2- to 4-hr interval, and by $4-8 \mathrm{hr}$ there is virtually no Bic-D RNA in the embryo. This pattern is similar to that observed for 

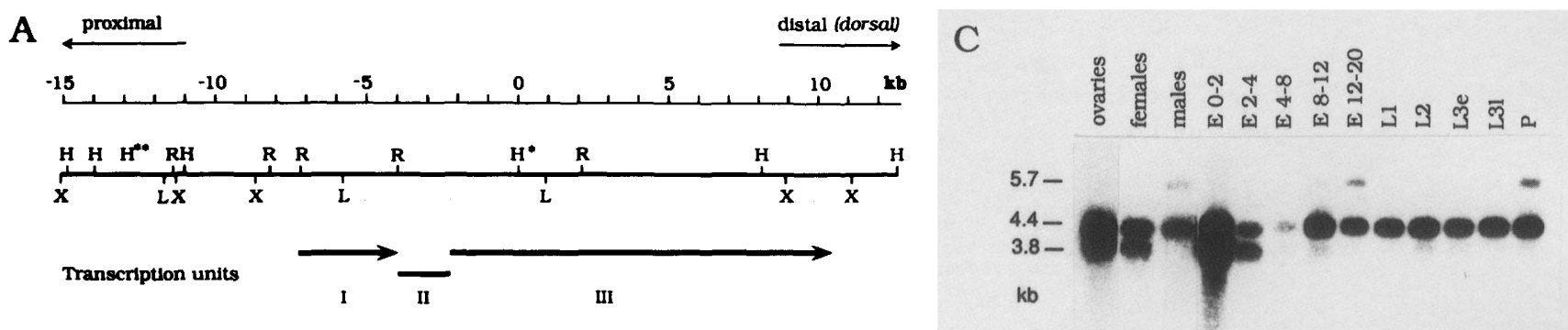

B Transformation

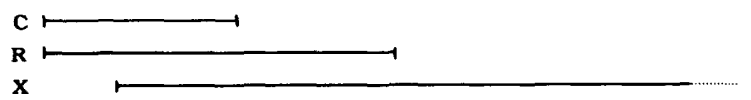

Figure 3. The genomic organization and the transcripts of the Bic-D region. $(A)$ Restriction map and transcription units, as determined by RNA blotting. Transcription units I and III encode ovarian-specific RNA species $\mid C$ and $B$. Suter, unpubl.). $\mathrm{H}^{\star}$ and $\mathrm{H}^{\star \star}$ are described in Fig. 2C. $\mathrm{H}^{\star}$ was chosen as zero (0) point. $(\mathrm{H})$ HindIII; (L) SalI; $(\mathrm{R})$ EcoRI; (X) XhoI. Only the relevant transcription units (I, II, III) are shown. Arrowheads indicate the direction of transcription. $(B)$ Genomic DNA sequences that were transformed into flies. Only X, a 30-kb XbaI fragment, rescued the female sterility of recessive Bic-D mutations. The proximal end of $\mathrm{X}$ is shown; the distal end is around position +20 to $+25 .(C)$ Autoradiograph of poly $|A|+$ RNA blots showing a developmental profile of the accumulation of transcripts from transcription unit III. The age of the embryos (E) is given in hours. (L1) First-instar larvae; (L2) second-instar larvae; (L3e) early third-instar larvae; (L3l) late third-instar larvae; (P) pupae. The first three lanes (dissected ovaries, whole adult females, and males) were probed with the nick-translated genomic $\lambda$ phage $B 1$, which contains sequences from +0.6 to +13.4 ; the other lanes, with the nick-translated HindIII-XhoI fragment (map position 8.8-8.0). A 3.8-kb RNA is present in females, ovaries, and early embryonic stages. Although the 4.4-kb transcript is found in all fractions, it seems to disappear around cellular blastoderm (Fig. 4D) and to come up again at $\sim 8 \mathrm{hr}$ of embryogenesis, as apparent from the faint band in the $\mathrm{E} 4-8$ fraction (which is not due to lack of RNA loaded) and the strong band in the following stage. The $5.7-\mathrm{kb}$ transcript is most abundant in males, late embryos and pupae.

other maternally supplied RNAs: The maternal transcripts persist during the very early embryonic cleavage stages but are degraded just prior to cellular blastoderm formation (Steward et al. 1988; Salz et al. 1989). After 8 $\mathrm{hr}$, the larger, 4.4-kb transcript reappears and is detected in all of the stages of the Drosophila life cycle examined, as well as in adult males. In addition, a third Bic-D transcript of $\sim 5.7 \mathrm{~kb}$ is found in late embryos, pupae, and adult males. Although the presence of Bic-D transcripts in females, ovaries, and early embryos might be expected from previous genetic analysis, it is not clear what functions the Bic-D RNAs may be providing at other stages in development and in adult males. In particular, all of the known Bic-D mutations have no obvious effects on viability and no apparent phenotype other than those affecting oogenesis and early embryogenesis.

\section{Localization of the Bic-D transcripts}

The Drosophila ovary consists of $\sim 16$ ovarioles subdivided into two morphologically distinct parts. In the germarium, a precursor cell divides into 16 cystocytes that stay interconnected through cytoplasmic bridges. One specific cystocyte becomes the oocyte and moves to the most posterior position, whereas the other cystocytes become nurse cells. This complex becomes surrounded by follicle cells and forms the egg chamber. The maturation of the egg chamber occurs in the vitellarium and has been subdivided into 14 stages (King 1970; Mahowald and Kambysellis 1980).

To examine the expression of the Bic-D gene during oogenesis, we hybridized a ${ }^{35}$ S-labeled Bic-D riboprobe to paraffin sections of wild-type ovaries (Ingham et al.
1985). We also hybridized a digoxigenin-labeled c15 cDNA probe to fixed whole ovaries and embryos (Tautz and Pfeifle 1989). The results of both experiments were comparable: In ovaries, we see hybridization in very young egg chambers (stages 1-2; see arrows in Fig. 4A). Up to stage 7 , signal is only found in the oocyte, where it is concentrated around the nucleus. The other cells show only background hybridization with the ${ }^{35} \mathrm{~S}$-labeled probe. At about stage 8 , we observe a striking increase of signal in the nurse cell complex; the accumulation of Bic-D RNA in these cells seems to increase up to stage 11 when the nurse cells empty their cytoplasmic contents into the oocyte. At stage 8 , the oocyte begins to increase in size due to the deposition of yolk and nurse cell contents, and it is during this period of growth (stages $8-10 \mathrm{~b}$ ) that the Bic-D transcript is localized to the anterior end of the oocyte (Fig. 4A,B). Analysis of cross sections, longitudinal sections, as well as whole-mount ovaries, indicates that the Bic-D RNA forms a cap covering the anterior end of the oocyte. By stage 11-12, when the deposition of nurse cell material and yolk into the oocyte is terminated, the RNA is no longer localized in the oocyte but is found nearly uniformly distributed (Fig. 4C). This distribution is maintained throughout the last stages of oogenesis. As shown in Figure 4D, Bic-D RNA is found uniformly distributed in early stages of embryogenesis up to the syncytial blastoderm stage when the level of RNA begins to drop. By cellular blastoderm stage, there is very little or no Bic-D RNA present (Fig. 4D).

\section{Structure of the Bic-D transcripts}

Both the 4.4- and the 3.8-kb maternal Bic-D transcripts 
persist in early embryos. To isolate cDNA clones corresponding to these transcripts, we screened a 0 - to $4-\mathrm{hr}$ embryonic cDNA library (Frigerio et al. 1986). Two of the $38 \mathrm{cDNAs}$ recovered from this screen were larger than $4 \mathrm{~kb}$ (c18 and c38), and because of their size, they are presumed to correspond to the larger $4.4-\mathrm{kb}$ transcript. Restriction mapping and Southern analysis revealed a second group of cDNA clones that are $0.5 \mathrm{~kb}$ shorter than $\mathrm{c} 18$ at the $3^{\prime}$ end. Because this is approximately the difference in length between the two Bic-D transcripts found in ovaries and early embryos, these two groups of cDNAs appear to be representative of the two transcripts. We chose one of these 'short' cDNAs (c15) and one of the 'large' cDNAs (c18) for sequence analysis.

Our analysis revealed that the two cDNAs are co- linear; however, as indicated in Figure 5, c18 extends farther than c15 at both the $3^{\prime}$ and $5^{\prime}$ ends. A polyadenylation signal (AATAAA; Proudfoot and Brownlee 1976) is present at position 3736 , and cDNA c15 ends at this signal sequence without a poly $(\mathrm{A})^{+}$tail. To determine whether this represents a bona fide 3 '-end signal, we sequenced the $3^{\prime}$ ends of three more cDNAs of the short group (c14, c28, and c32, Fig. 5). One of these cDNAs, c28, ends 24 nucleotides after this signal with a short poly $(\mathrm{A})^{+}$stretch. On the basis of these results, we believe that this polyadenylation signal is used in ovaries to generate the smaller $3.8 \mathrm{~kb}$ transcript. The large cDNA c18 extends 433 bp beyond this polyadenylation site to a poly $(\mathrm{A})^{+}$tail at position 4193 . Another polyadenylation signal is $31 \mathrm{bp}$ upstream of this tail. These findings would suggest that the 3.8 - and the $4.4-\mathrm{kb} B i c-D$

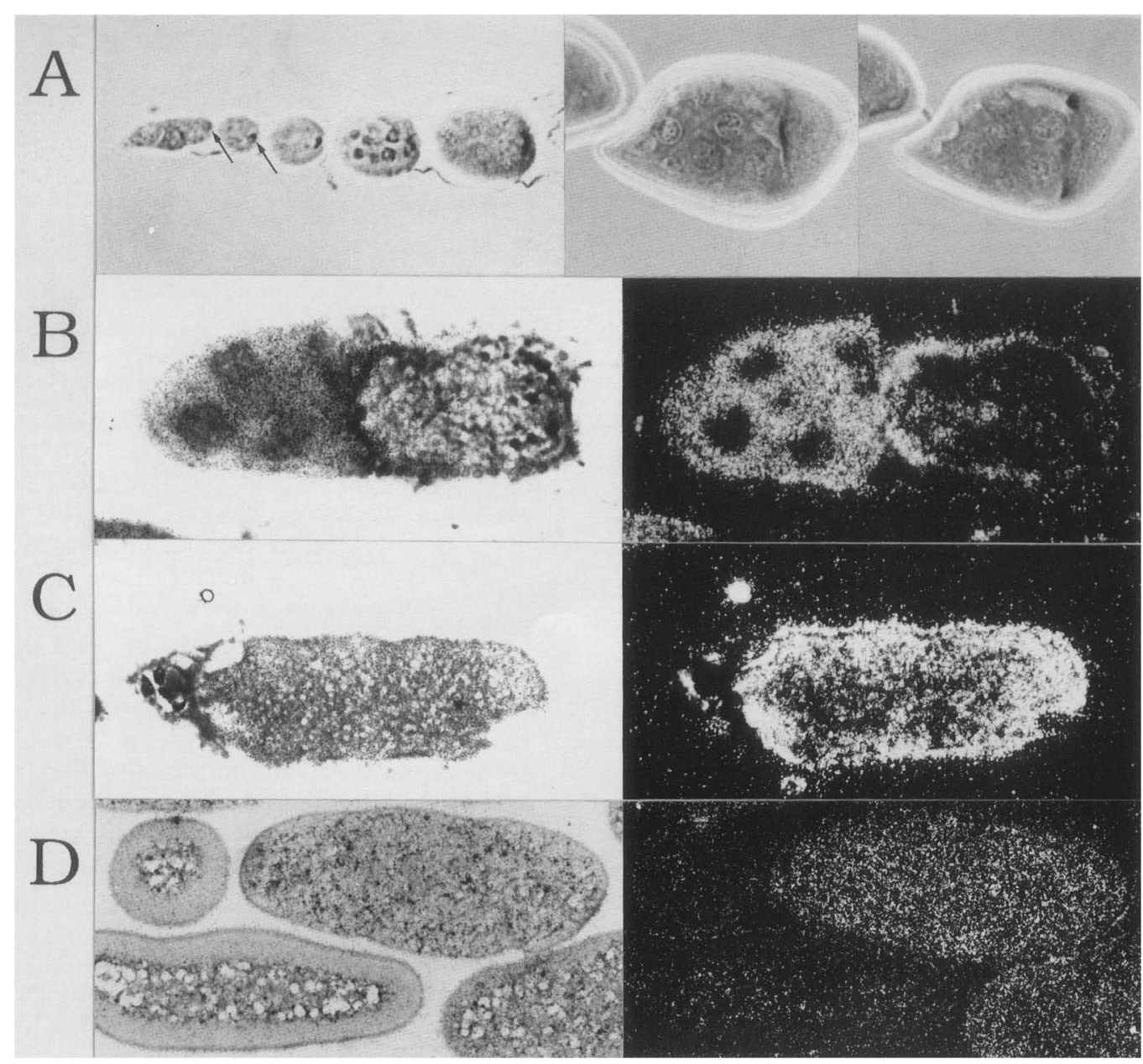

Figure 4. In situ hybridization of a Bic-D probe to wild-type ovaries and embryos. (A) Whole-mount preparation of an ovariole (egg chamber stages $1-81$, which was hybridized with a digoxigenin-labeled cDNA c15 probe. Arrows indicate staining at the posterior end of approximately stage 1 and stage 2 egg chambers. At stage 8, the Bic-D transcript is localized to the anterior end of the oocyte. The same egg chamber is shown focused onto two different planes. $(B-D)$ Section through egg chambers and embryos hybridized with a ${ }^{35}$ S-labeled RNA probe, transcribed from the $0.8-\mathrm{kb}$ HindIII-Xhol fragment (map position 8.8-8.0; Fig. 3). Bright-field (left) and darkfield (right) micrographs. (B) Bic-D RNA is present in the nurse cell cluster (left) and at the anterior end of the oocyte (stage 10b-11). It started to spread out posteriorly along the circumference of the oocyte. $(C)$ At stage 13, the Bic-D RNA is found in the entire oocyte with no apparent concentration differences between anterior (left) and posterior (right). (D) In preblastoderm embryos, the Bic-D RNA is uniformly distributed and disappears at cellular blastoderm. 
transcripts in ovaries and early embryos differ in length (at least in part) because of the use of a different poly(A) ${ }^{+}$ addition signal in the primary Bic-D transcript. Because no other structural difference was evident in our Bic-D cDNAs, it is conceivable that the use of different poly $(\mathrm{A})^{+}$addition sites may account for the difference in length $(600 \mathrm{bp})$ of the two RNAs observed in our Northern blots.
Because the same single large open reading frame (ORF) is found in both cDNAs c15 and c18 (with the exception discussed below), it would seem that the large and small Bic-D ovarian transcripts must encode the same protein species. The first methionine within this ORF (position 935) fits the initiator methionine consensus sequence (Kozak 1984; Cavener 1987). The ORF is 782 amino acids long, and the predicted protein has a

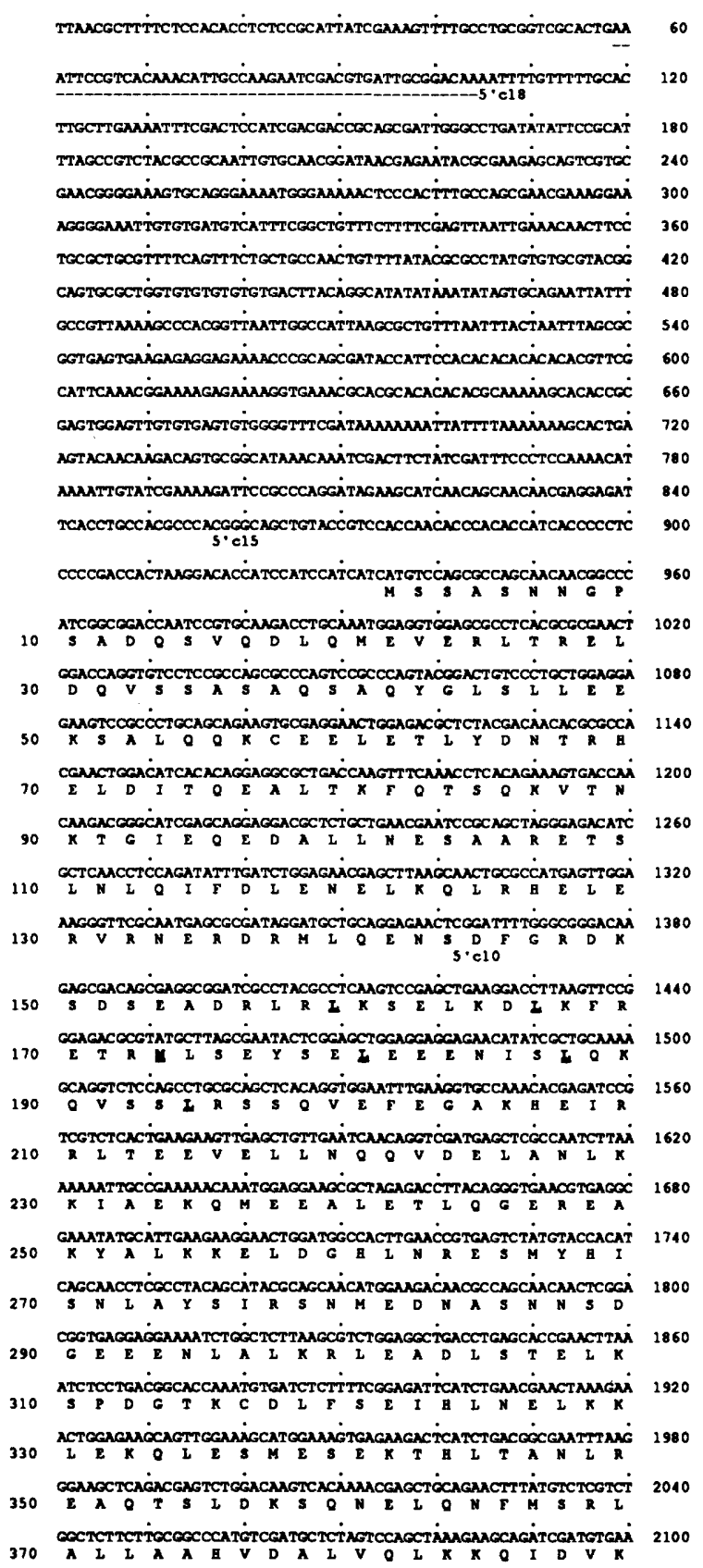

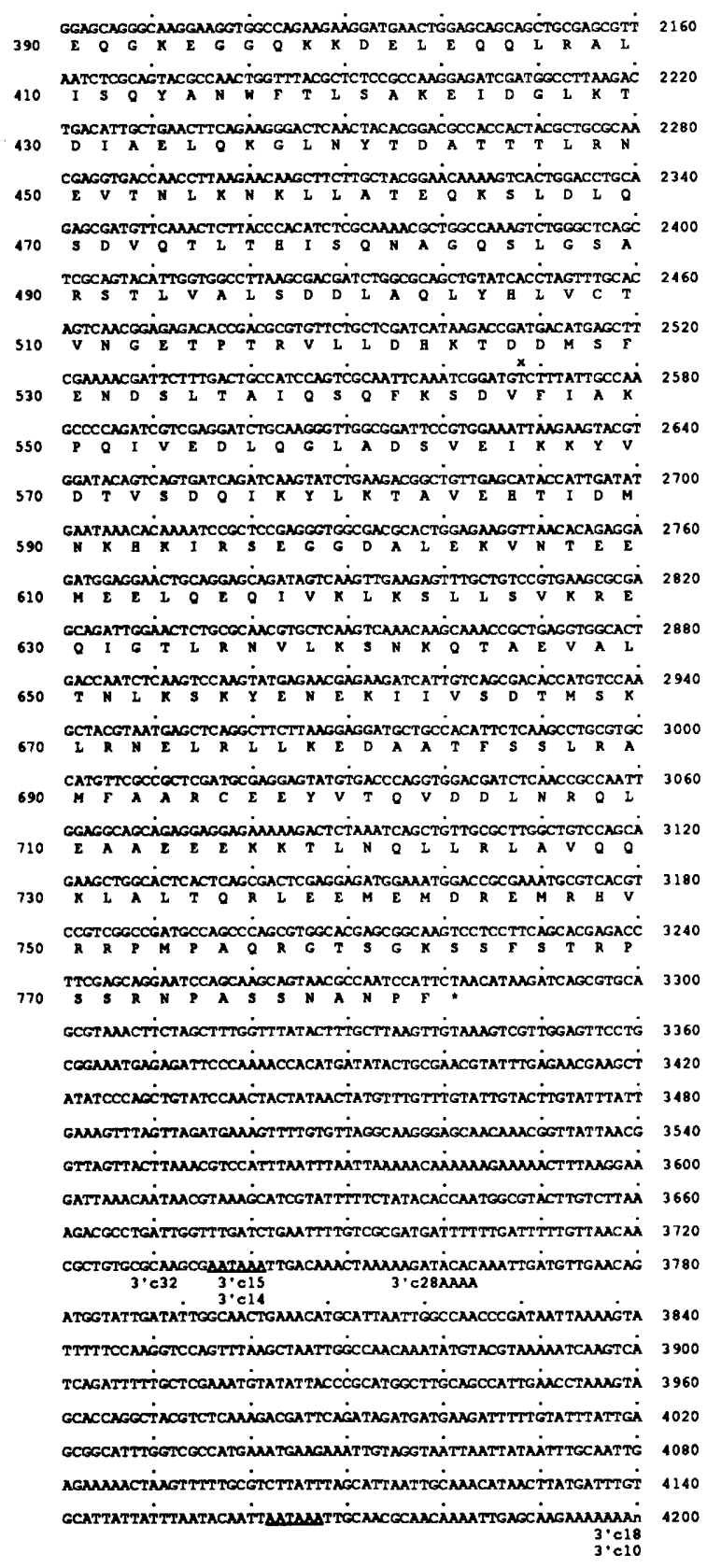

Figure 5. Sequence of the Bic-D transcript and the predicted Bic-D protein. The sequence starts at map position -2.25 (Fig. 3A). The $5^{\prime}$ sequence is derived from the genomic DNA, the sequence from the DNA position 105 to the 3 ' end from cDNA c18. cDNAs c18, c30, and c38 start around DNA position 60 but show rearrangements in the $5^{\prime}$ region, as indicated by dashes for $\mathrm{c} 18$. The $5^{\prime}$ or $3^{\prime}$ ends of the cDNAs mentioned in the text are indicated. The two polyadenylation signals that seem to be used in ovaries are underlined. The leucine zipper motif is printed in boldface type and underlined. $\mathrm{x}$ in DNA position 2568 marks the $\mathrm{T} \rightarrow \mathrm{C}$ substitution (which changes $\mathrm{Val}$ into $\mathrm{Ala}$ ) found in cDNA cl5 and discussed in the text. 
molecular mass of $89 \mathrm{kD}$ and an isoelectric point (pI) of 4.93.

Within the coding region, cDNAs c15 and c18 differ at 5 nucleotide positions. Four of them do not change the predicted amino acid (data not shown). The fifth polymorphism changes $\mathrm{Val}_{545}$ into Ala in cDNA c15. It is likely that this substitution in $\mathrm{c} 15$ is caused by a reverse transcription error, because another cDNA, c10, also encodes a valine residue in this position but otherwise has the same sequence polymorphisms as c15.

\section{Structure of the predicted Bic-D protein}

A search of current sequence data bases reveals that the predicted amino acid sequence of Bic-D shows some similarity to the rod region of myosin heavy chain $(\mathrm{MHC})$ and to lamin, desmin, keratin, and other intermediate filament proteins (Parry et al. 1977; Geisler et al. 1982; McLachlan and Karn 1983; Steinert et al. 1985; McKeon et al. 1986). Shown in Figure 6 is an optimal alignment between the rod portion of Caenorhabditis elegans MHC (Karn et al. 1983) and the predicted amino acid sequence of Bic-D. Although there is only $\sim 18 \%$ identity between the predicted BiC-D protein $(782$ amino acids) and the rod portion of $C$. elegans MHC, this comparatively low level of identity may be significant. First, the similarity between the two proteins extends over essentially the entire length of the BiC-D protein 1775 amino acids). Second, comparable results are obtained when the predicted $B i c-D$ amino acid sequence is aligned to the rod portion of other MHCs. Third, this part of the MHC is generally less well conserved in sequence between different organisms, and the similarity between tail regions of different myosins can be as low as $25 \%$ identity (Warrick and Spudich 1987). These observations suggest that Bic-D may be a member of a family of proteins that share sequence and structural similarities with the rod domain of $\mathrm{MHC}$.

The common feature of fibrous proteins such as MHC, lamin, desmin, and keratin is an extended $\alpha$-helical coiled-coil structure that is built with a characteristic heptad repeat pattern, a,b,c,d,e,f,g, with hydrophobic residues in position a and $d$. The same motif has been found more recently in other proteins that share similarity to the predicted Bic-D protein: Drosophila kinesin heavy chain, yeast rad50 gene product, and C. elegans paramyosin (Alani et al. 1989; Kagawa et al. 1989; Yang et al. 1989 ). We analyzed the predicted Bic-D protein sequence for the presence of extended heptad repeats. At least three regions, free of helix-breaking proline residues and with a high probability of forming extended $\alpha$-helical structures, were found to fit this pattern (Fig. 7). These are heptad 1 (H1) from $\mathrm{Leu}_{194}$ to $\mathrm{Gly}_{259}, \mathrm{H} 2$ from $\mathrm{Leu}_{327}$ to $\mathrm{Leu}_{382}$, and $\mathrm{H} 3$ from $\mathrm{Val}_{663}$ to $\mathrm{Met}_{740}$ (Fig. 7A,B). We adopted the histogram representation of Yang et al. (1989) and McLachlan and Karn (1983) to show the distribution of hydrophobic (Fig. 7C), negatively charged (Fig. 7D), and positively charged (Fig. 7E) residues within these three potential $\alpha$-helical coiled-coil domains with a minor modification: The percentage of a given type of

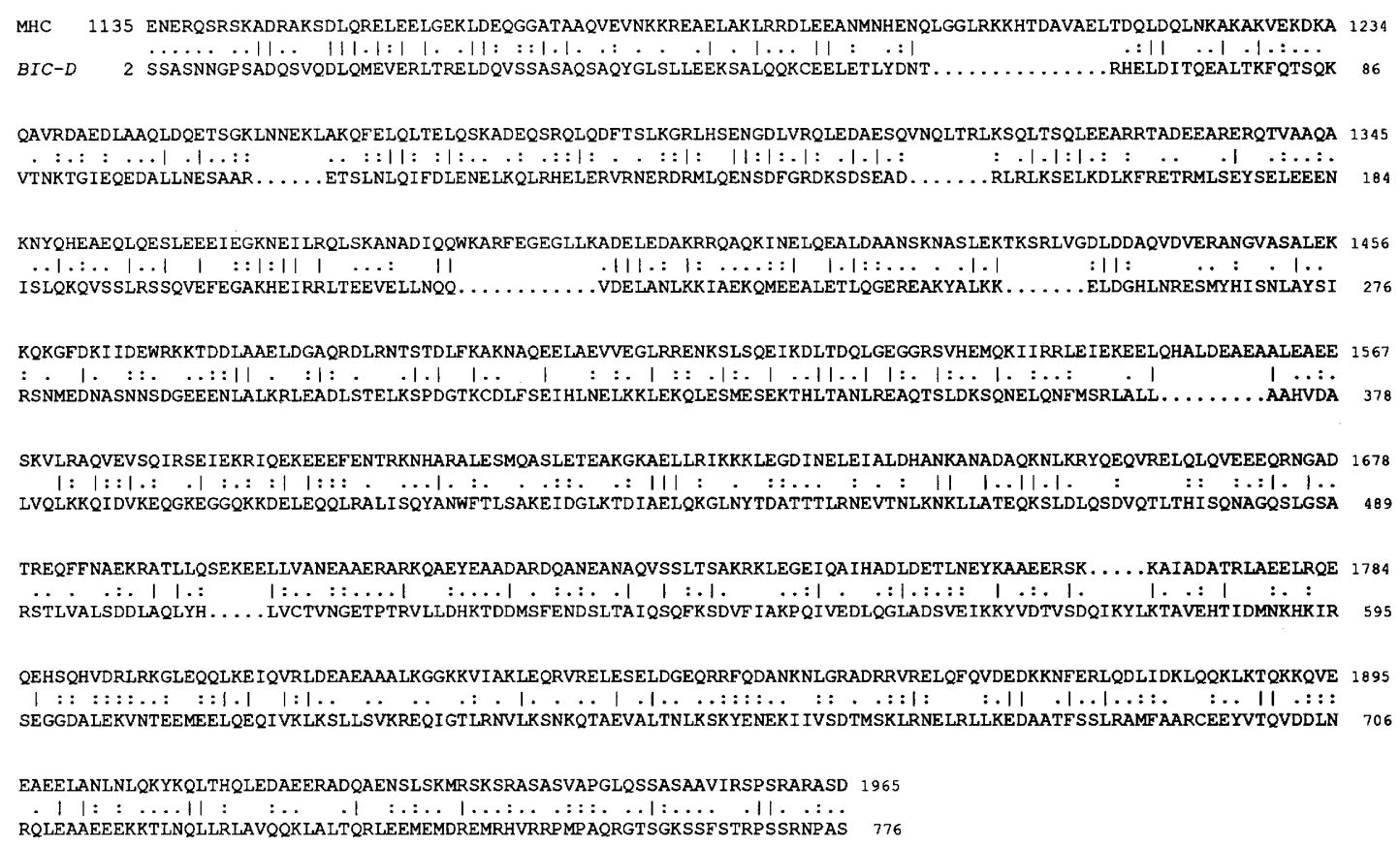

Figure 6. A comparison of the amino acid sequences of the predicted translation products of C. elegans myosin heavy chain (Karn et al. 1983) and the D. melanogaster Bic-D gene. The alignment was done with the program BESTFIT (Devereux et al. 1984), using a gap weight of 6.0, a gap length weight of 0.3 , and the Dayhoff symbol comparison table (Schwartz and Dayhoff 1978), as modified by Gribskov and Burgess (1986). Vertical bars between the aligned sequences indicate identical amino acids, colons indicate high similarities, and dots show weak similarities. 
residue is shown rather than the absolute number. The most prominent feature of this repeat is a strong bias toward hydrophobic residues in positions a and d, which form the core of an $\alpha$-helical coiled coil. These heptad regions fit further criteria for $\alpha$-helical coiled-coil structures: No negatively charged residues are found in position a, and no positively charged residues are found in position $\mathrm{d}$ (Fig. 7D,E).

A potentially significant difference to $\mathrm{MHC}$ tails might be that these $\alpha$-helical regions do not span the entire protein but are broken up into several shorter regions. According to Cohen and Parry (1986), if the ratio of charged to apolar residues within a heptad repeat is close to 1.0 , an elongated structure is possible. If the ratio is less than $\sim 0.6$, a globular shape will probably result. For $\mathrm{Hl}$, a ratio of 1.2 was calculated from the sequence shown in Figure 7B, suggesting an elongated structure for $\mathrm{H} 1$. For $\mathrm{H} 3$, the ratio of charged to apolar residues is 0.8 , which does not allow a prediction. $\mathrm{H} 2$ might be elongated over the amino-terminal 10-12 helix turns (5-6 heptad repeats) and take up a globular shape in its carboxy-terminal region. A ratio of 1.3 was calculated for the first six repeats, and a ratio of 0.2 was calculated for the last two.

Although other regions within the predicted Bic-D protein might form this type of $\alpha$-helix, they are either shorter or show a less pronounced heptad repeat pattern (data not shown). Extended heptad repeats support the formation of coiled-coil dimerization of the fibrous proteins or stabilize intramolecular structures in a variety of proteins with different functions (for review, see Cohen and Parry 1986). One of the regions with a less pronounced coiled-coil pattern may be involved in another type of protein-protein interaction: A leucine for methionine) residue is present in every seventh position from $\mathrm{Leu}_{159}$ to $\mathrm{Leu}_{194}$. Only the third leucine is substituted by methionine. Such a structural motif was described as the leucine zipper, and it was proposed to support dimerization of closely related proteins (Buckland and Wild 1989; Landschulz et al. 1989).

\section{Discussion}

Previous genetic studies have suggested that the Bic-D gene is involved in several different processes during oogenesis. In this respect, it may be of interest that our in situ hybridization experiments indicate that Bic-D is expressed in at least two different phases in the ovary (Fig. 4). In the first phase, the Bic-D transcript accumulates in only a single cell of the egg chamber. The localized Bic- $D$ transcript can first be detected at stage $1-2$, and this pattern of accumulation persists up until about stage $7-8$. In the early stages $(1-4)$, the labeled cell is at the very posterior end of the egg chamber and presumably corresponds to the oocyte. At later stages (5-7) when the oocyte is readily distinguished from the 15 nurse cells, it is clear that only the oocyte contains the $B i c-D$ transcript. Both of the recessive loss-of-function Bic-D alleles, PA66 and R26, cause a block at a point very early in oogenesis: No oocyte develops and all 16
A

$$
\begin{aligned}
& \text { turns } \\
& \text { alpha helices } \\
& \text { beta sheets }
\end{aligned}
$$

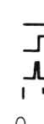

B
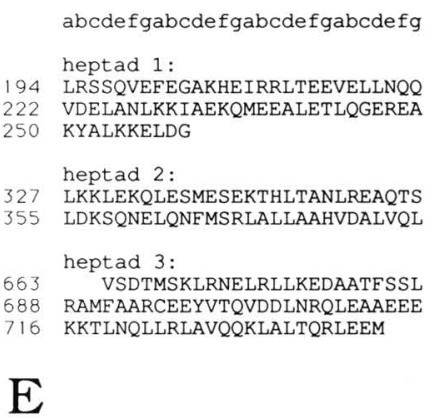

$\%$ Positively Charged Residues

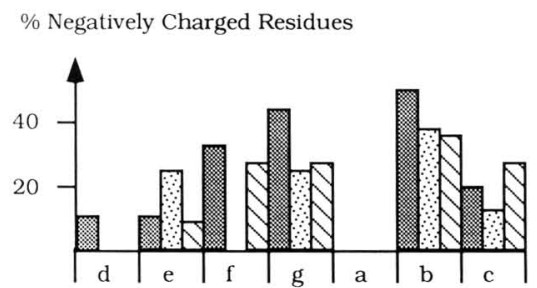

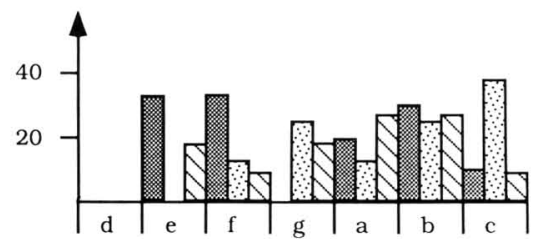

Figure 7. Secondary structure predictions for the Bic-D protein. $(A \mid$ Possible secondary structure calculated according to Garnier et al. (1978) and displayed by the GCG program PlotStructure (Devereux et al. 1984). For each region within the protein, one of the three structures shown or a random coil structure is predicted according to the highest probability. This is displayed by the high value of the corresponding line. $(B)$ Heptad repeat sequences. The numbering of the residues is the same as that in Figs. 5 and 6 . The position of each residue is given as a, b, c, d, e, f, g. $(C-E)$ Histograms showing the distribution of hydrophobic residues $(C)$, negatively charged residues $(D)$, and positively charged residues $(E)$ within the repeats. The signatures used for the different heptads are shown in $C$. (Hydrophobic residues, F, I, L, M, V, W, Y; negatively charged residues, D, E; positively charged residues, H, K, R). None of the heptads contains a proline residue. 
cystocytes differentiate into nurse cells (Fig. 1B). Functional Bic-D product is therefore required for the differentiation of the oocyte. In the germarium this could involve the exclusive expression of the Bic-D gene in presumptive oocytes, where it perhaps serves to distinguish this cell from the other cystocytes. Unfortunately, our in situ hybridization experiments were not sensitive enough to detect Bic-D transcripts in the germarium, and other techniques will be required to test this model. In addition, it will be of interest to determine whether the presence of Bic-D transcripts in the oocyte between egg chamber stages 1 and 7 reflects some type of 'maintenance' function for Bic-D in the development of the oocyte.

In the second phase, the pattern of accumulation of the Bic-D transcript changes dramatically. Beginning at about stage 8 , we observe a continuous increase in labeling over the nurse cells, suggesting that the expression of the Bic-D gene is activated in the polyploid nurse cell nuclei. This newly synthesized Bic-D RNA appears to be transported from the nurse cells into the oocyte, where it accumulates in a cap around the anterior end of the oocyte in the period between stages 8 and 10b. Similar anterior localization in the oocyte has been described for the mRNAs of $f_{S}(1) K 10$ (Haenlin et al. 1987) and bicoid (Berleth et al. 1988). Macdonald and Struhl (1988) showed that sequences within the long 3'-untranslated sequence (trailer) of the bicoid mRNA are responsible for its localization within the oocyte, and conceivably, the Bic-D transcript may contain analogous sorts of cis-acting elements that function in its localization.

The presence and localization of the Bic-D RNA at these later stages suggest that the wild-type Bic-D product may have an additional function during this period of oocyte development. This view is supported by two observations: First, the temperature-sensitive period of the Bic-D dominant phenotype is late in oogenesis; second, the double abdomen phenotype is most penetrant in embryos from homo- or hemizygous Bic- $D$ females but is reduced in offspring of $B i c-D /+$ and even further reduced in offspring of $B i c-D /+1+$ females (Mohler and Wieschaus 1986). Therefore, it seems that the wild-type gene product of Bic-D competes with the $B i c-D$ mutant gene product in stages after the oocyte has been determined but when the polarity of the oocyte can still be affected by gain-of-function alleles.

These dominant Bic- $D$ alleles affect the localization of anterior and posterior factors in the embryo: In Bic- $D$ embryos (embryos from Bic-D mothers), the anteriorly localized bicoid mRNA is less stable, and the bicoid protein, responsible for positional information in the anterior part of the embryo, is absent (Driever and Nüsslein-Volhard 1988a,b). Lehmann and Nüsslein-Volhard (1986) could also demonstrate that posterior factors are mislocalized to the anterior pole of Bic-D embryos, where they are able to generate a second posterior center. These mislocalized posterior activities may alter subsequent developmental fate by inactivating or destabilizing anterior activities anteriorly. Indeed, nanos, one of the posterior genes, has been shown to repress the maternally supplied anterior activity of the gap gene hunchback in the posterior region (Tautz 1988; Hülskamp et al. 1989; Irish et al. 1989; Struhl 1989). The complex rearrangement of anterior and posterior activities caused by the dominant Bic-D mutations suggests that the Bic-D protein may interact with one or more of the components involved in the establishment of anteroposterior polarity, perhaps functioning to localize or stabilize these components properly in the developing egg chamber.

The sequence analysis of the Bic-D gene reveals that it encodes a protein with structural features that would be consistent with some type of role in determining the organization of the oocyte. The predicted Bic-D protein shows similarity to the myosin heavy chain (MHC) tail. MHC is composed of a globular head and a coiled-coil tail region. By comparing the two sequences, we could only find similarity to the tail region, indicating that there are clear differences between the two related proteins (Fig. 6). The identity of the Bic-D protein to different MHC tails is $18 \%$ at the most. Though this figure is rather low, it should be noted that the amino acid identity in MHC tails can be as low as $25 \%$ in distantly related organisms (Warrick and Spudich 1987). Amino acids that are identical in the two proteins are more or less evenly distributed throughout the Bic-D protein and the MHC tail, and at least two different alignments result in the same overall identity. In MHC, two $\alpha$-helices coil around each other to form the rod-like tail. The fundamental structure of this amphipathic helix is a heptapeptide repeat with a characteristic distribution of hydrophobic and charged residues (McLachlan and Karn 1983). Extended heptad repeats of the same type are also present in the predicted Bic-D protein (Fig. 7). Heptad repeats are a common motif in proteins. They generally support coiled-coil formation between different domains of a protein or between two protein molecules, as is the case for MHC (Steinert et al. 1985; Cohen and Parry 1986; Murre et al. 1989). It seems likely that the Bic-D heptad repeats are also used for coiled-coil interactions leading to (e.g., homo-) dimer formation and possibly higher order aggregates similar to MHC filaments. This could explain how the wild-type Bic-D gene product can suppress the effects of the mutant gain-of-function gene products.

The predicted Bic-D protein also contains regions that have no apparent heptad repeats. These could mediate interactions with other gene products involved in oocyte differentiation and embryonic development. Whether these interactions are responsible for the localization of different maternal gene products will be the object of further investigations.

\section{Methods}

Genetic recombination and fly stocks

Most fly stocks and markers have been described elsewhere (Lindsley and Grell 1968; Mohler and Wieschaus 1986; Steward and Nüsslein-Volhard 1986). Dominant maternal-effect alleles of Bic-D are 71.34, IIIE48, and YC67. Recessive female sterile 
alleles are R26, a revertant of 71.34 and PA66. Df(2L)TW119 fails to complement $d l$ and Bic-D and is homozygous lethal.

The protocol described by Steward and Nüsslein-Volhard (1986) was followed for the recombination analysis. Recombination was allowed to occur in females that were trans-heterozygous for $d l^{8}$ and PA66. These females were crossed to $D f(2 L) T W 119$ males. In the next generation, females were tested for fertility (Fig. 2A). Only females that inherited a recombinant chromosome (i.e., $\mathrm{dl}^{+}$and $\mathrm{Bic}-\mathrm{D}^{+}$) were fertile. Fertile recombinants were crossed to $b \mathrm{pr} c n \mathrm{sca}$ for testing the presence of flanking markers $b$ and $p r$. They were also backcrossed to $D f(2 L) T W 119$ to establish lines that are homo- or hemizygous for the recombined $d l^{+} B i c-D^{+}$region. Flies were kept at $25^{\circ} \mathrm{C}$ or at room temperature.

\section{Genomic and cDNA libraries, general methods}

Recombinant genomic $\lambda$ libraries used are described elsewhere (Steward et al. 1984; Riggleman et al. 1989). Phage used for this work were $\mathrm{B} 1(0.6$ to 13.4$), \mathrm{B} 2(-8.4$ to 7$)$, and $\mathrm{B} 3(-16.6$ to -2 ). The recombinant Oregon- $\mathrm{R}$ cosmid library was obtained from L. Brennan (Princeton). cDNAs were recovered from a 0to 4-hr embryonic $\lambda$ gt 10 library (Frigerio et al. 1986).

Standard cloning and labeling techniques were done according to Maniatis et al. (1982). Single-stranded riboprobes (Melton et al. 1984) were used to determine the direction of transcription and for in situ hybridization. Southern and Northern hybridizations were carried out on GeneScreen and GeneScreen Plus membranes (New England Nuclear) with the hybridization buffer of Church and Gilbert (1984). Isolation of RNA and Northern hybridizations were essentially done according to Doerig et al. (1988), except that the glyoxal was removed by a procedure that quantitatively removes glyoxal from RNA in solution without damaging the RNA (A. Zaug, pers. comm.). After transfer onto GeneScreen membranes, UV crosslinking, and baking, the membrane was incubated for $2 \mathrm{hr}$ at $50^{\circ} \mathrm{C}$ in $0.3 \mathrm{M}$ Tris base.

For in situ hybridization, tissue sections $(6 \mu \mathrm{m})$ were prepared and hybridized with a ${ }^{35} \mathrm{~S}$-labeled antisense RNA; controls were prepared with a sense strand probe, as described by Ingham et al. (1985). Whole-mount in situ hybridization to ovaries and embryos was performed as described by Tautz and Pfeifle (1989).

\section{Transformation of Drosophila}

The genomic restriction fragment $\mathrm{X}$ (Fig. 3B) is the proximal $30-\mathrm{kb} X b a \mathrm{I}$ fragment purified from the genomic cosmid clone B25 (L. Brennan, unpubl.). It was directly subcloned into the single $X b a I$ site of the $\mathrm{pCaSpeR}$ transformation vector, which contains a $w^{+}$marker (Pirrotta 1988). The Xbal-EcoRI fragment in the multicloning site of $\mathrm{pCaSpeR}$ was replaced by the corresponding fragment of pUC18, thereby introducing a singular Asp718 site for subcloning the genomic fragments $R$ and $\mathrm{C}$ (Fig. 3B) out of the Bluescript vector.

P-element-mediated transformation (Spradling and Rubin 1982) was done with the genomic transposase source (Robertson et al. 1988). Lines of flies with $w^{+}$inserts were crossed to either $w ; D f(2 L) T W 119 b$ or $d p / C y O b w ; R 26 b b p / C y O b$ flies or $w ; P A 66 \mathrm{cn} \mathrm{sca/CyO}$ flies. These transformant lines were used to test for rescue of female sterility caused by homo-, trans-hetero- or hemizygous PA66 and R26 mutations.

\section{Structural analysis}

For DNA sequencing, nested deletions were produced by treat- ment with exonuclease III and S1 nuclease (Henikoff 1987), using the Bluescript vector (Stratagene). Single-stranded DNA was sequenced by the method of Sanger et al. (1977), with the modifications for the Sequenase system (U.S. Biochemical). The sequence data base search was done with the TFASTA program (Lipman and Pearson 1985), and the optimal alignment was done with the program BESTFIT (Devereux et al. 1984). Programs by Staden (Staden 1986) and GCG (Devereux et al. 1984) were used for the structural analysis of nucleic acid and protein sequences.

\section{Acknowledgments}

We thank Paul Schedl for his interest and enthusiasm and Iva Greenwald, P. Schedl, and Eric Wieschaus for stimulating discussions and critical reading of the manuscript. We thank D. Winkelmann and J. Schwarzbauer for valuable discussion and the Horace W. Goldsmith Foundation for assistance. We thank L. Brennan for cosmid B25, L. Bell, R. Dörig, R. Kellum, L. Keyes, S. Parks, T. Schüpbach, and B. Zerges for help during various parts of this work, and G. Gray for fly food. B. Suter was supported by a fellowship from the Swiss National Science Foundation. This work was supported by grant 5R01 HD 18055-06 from the National Institutes of Health and by a grant from the March of Dimes to P.S.

\section{References}

Alani, E., S. Subbiah, and N. Kleckner. 1989. The yeast RAD50 gene encodes a predicted $153-\mathrm{kD}$ protein containing a purine nucleotide-binding domain and two large heptad-repeat regions. Genetics 122: 47-57.

Berleth, T., M. Burri, G. Thoma, D. Bopp, S. Richstein, G. Frigerio, M. Noll, and C. Nüsslein-Volhard. 1988. The role of localization of bicoid RNA in organizing the anterior pattern of the Drosophila embryo. EMBO 1. 7: 1749-1756.

Buckland, R. and F. Wild. 1989. Leucine zipper motif extends. Nature 338: 547.

Bull, A. 1966. Bicaudal, a genetic factor which affects the polarity of the embryo of Drosophila melanogaster. /. Exp. Zool. 161: 221-242.

Cavener, D.R. 1987. Comparison of the consensus sequence flanking translational start sites in Drosophila and vertebrates. Nucleic Acids Res. 15: 1353-1361.

Church, G.M. and W. Gilbert. 1984. Genomic sequencing. Proc. Natl. Acad. Sci. 81: 1991-1995.

Cohen, C. and D.A.D. Parry. 1986. Alpha-helical coiled coilsA widespread motif in proteins. TIBS 11: 245-248.

Devereux, J., P. Haeberli, and O. Smithies. 1984. A comprehensive set of sequence analysis programs for the VAX. Nucleic Acids Res. 12: 387-395.

Doerig, R.E., B. Suter, M. Gray, and E. Kubli. 1988. Identification of an amber nonsense mutation in the rosy ${ }^{516}$ gene by germline transformation of an amber suppressor tRNA gene. EMBO J. 7: 2579-2584.

Driever, W. and C. Nüsslein-Volhard. 1988a. A gradient of bicoid protein in Drosophila embryos. Cell 54: 83-93.

- 1988b. The bicoid protein determines position in the Drosophila embryo in a concentration-dependent manner. Cell 54: 95-104.

Frigerio, G., M. Burri, D. Bopp, S. Baumgartner, and M. Noll. 1986. Structure of the segmentation gene paired and the Drosophila PRD gene set as part of a gene network. Cell 47: $735-746$. 
Frohnhöfer, H.G., R. Lehmann, and C. Nüsslein-Volhard. 1986. Manipulating the anteroposterior pattern of the Drosophila embryo. J. Embryol. Exp. Morphol. 97(sup): 169-179.

Garnier, J., D.J. Osguthorpe, and B. Robson. 1978. Analysis of the accuracy and implications of simple methods for predicting the secondary structure of globular proteins. J. Mol. Biol. 120: 97-120.

Geisler, N., E. Kaufman, and K. Weber. 1982. Protein chemical characterization of three structural distinct domains along the protofilament unit of desmin $10 \mathrm{~nm}$ filaments. Cell 30: $277-286$.

Gribskov, M. and R.R. Burgess. 1986. Sigma factors from E. coli, B. subtilis, phage SP01, and phage T4 are homologous proteins. Nucleic Acids Res. 14: 6745-6763.

Haenlin, M., C. Roos, A. Cassab, and E. Mohier. 1987. Oocytespecific transcription of $\mathrm{fs}(1) \mathrm{K} 10$ : A Drosophila gene affecting dorsal-ventral developmental polarity. EMBO $I$. 6: $801-807$.

Henikoff, S. 1987. Unidirectional digestion with exonuclease III in DNA sequence analysis. Methods Enzymol. 155: 156165.

Hülskamp, M., C. Schröder, C. Pfeifle, H. Jäckle, and D. Tautz. 1989. Posterior segmentation of the Drosophila embryo in the absence of a maternal posterior organizer gene. Nature 338: $629-632$.

Ingham, P.W., K.R. Howard, and D. Ish-Horowicz. 1985. Transcription pattern of the Drosophila segmentation gene hairy. Nature 318: 439-445.

Irish, V., R. Lehmann, and M. Akam. 1989. The Drosophila posterior group gene nanos functions by repressing hunchback activity. Nature 338: 646-648.

Kagawa, H., K. Gengyo, A.D. McLachlan, S. Brenner, and J. Karn. 1989. Paramyosin gene (unc-15) of Caenorhabditis elegans molecular cloning, nucleotide sequence and models for thick filament structure. J. Mol. Biol. 207: 311-333.

Kalthoff, K. and K. Sander. 1968. Der Entwicklungsgang der Missbildung 'Doppelabdomen' im partiell UV-bestrahlten Ei von Smittia parthenogenetica (Dipt., Chironomidae). Wilhelm Roux's Arch. 161: 129-146.

Kandler-Singer, I. and K. Kalthoff. 1976. RNase sensitivity of an anterior morphogenetic determinant in an insect egg (Smittia sp., Chironomidae, Diptera. Proc. Natl. Acad. Sci. 73: 3739-3743.

Karn, J., S. Brenner, and L. Barnett. 1983. Protein structural domains in the Caenorhabditis elegans unc- 54 myosin heavy chain gene are not separated by introns. Proc. Natl. Acad. Sci. 80: 4253-4257.

King, R.C. 1970. Ovarian development in Drosophila melanogaster. Academic Press, New York.

Kozak, M. 1984. Compilation and analysis of sequences upstream from the translational start site in eukaryotic mRNAs. Nucleic Acids Res. 12: 857-872.

Landschulz, W.H., P.F. Johnson, and S.L. McKnight. 1989. The DNA binding domain of the rat liver nuclear protein C/EBP is bipartite. Science 243: $1681-1688$.

Lehmann, R. and C. Nüsslein-Volhard. 1986. Abdominal segmentation, pole cell formation, and embryonic polarity require the localized activity of oskar, a maternal gene in Drosophila. Cell 47: 141-152.

Lindsley, D. and R. Grell. 1968. Genetic variations of Drosophila melanogaster. Carnegie Inst. Wash. Publ. 627.

Lipman, D.J. and W.R. Pearson. 1985. Rapid and sensitive protein similarity searches. Science 227: 1435-1441.

Macdonald, P.M. and G. Struhl. 1988. Cis-acting sequences responsible for anterior localization of bicoid mRNA in Drosophila embryos. Nature 336: 595-598.
Mahowald, A.P. and M.P. Kambysellis. 1980. Oogenesis. In The genetics and biology of Drosophila, vol. $2 \mathrm{~d}$ (ed. M. Ashburner and T.R.F. Wright), pp. 141-224. Academic Press, New York.

Maniatis, T., E.R. Fritsch, and J. Sambrook. 1982. Molecular cloning: A laboratory manual. Cold Spring Harbor Laboratory, Cold Spring Harbor, New York.

McKeon, F.D., M.W. Kirschner, and D. Caput. 1986. Homologies in both primary and secondary structure between nuclear envelope and intermediate filament proteins. Nature 319: 463-468.

McLachlan, A.D. and J. Karn. 1983. Periodic features in the amino acid sequence of nematode myosin rod. J. Mol. Biol. 164: 605-626.

Melton, D.A., P.A. Krieg, M.R. Rebagliati, T. Maniatis, K. Zinn, and M.R. Green. 1984. Efficient in vitro synthesis of biologically active RNA and RNA hybridization probes from plasmids containing a bacteriophage SP6 promoter. Nucleic Acids Res. 12: 7035-7056.

Mohler, J. and E.F. Wieschaus. 1985. Biocaudal mutations of Drosophila melanogaster: Alternation of blastoderm cell fate. Cold Spring Harbor Symp. Quant. Biol. 50: 105-111.

- 1986. Dominant maternal-effect mutations of Drosophila melanogaster causing the production of double-abdomen embryos. Genetics 112: 803-822.

Murre, C., P. Schonleber McCaw, and D. Baltimore. 1989. A new DNA binding and dimerization motif in immunoglobin enhancer binding, daughterless, MyoD and myc proteins. Cell 56: 777-783.

Nüsslein-Volhard, C. 1977. Genetic analysis of pattern-formation in the embryo of Drosophila melanogaster: Characterization of the maternal-effect mutant biocaudal. Wilhelm Roux's Arch. Dev. Biol. 183: 249-268.

Nüsslein-Volhard, C., H.G. Frohnhöfer, and R. Lehmann. 1987. Determination of anteroposterior polarity in Drosophila. Science 238: 1675-1681.

Parry, D.A.D., W.G. Crewther, R.D.B. Fraser, and T.P. MacRae. 1977. Structure of alpha-keratin: Structural implication of the amino acid sequences of type I and type II chain segments. J. Mol. Biol. 113: 449-454.

Pirrotta, V. 1988. Vectors for P-mediated transformation in Drosophila. In Vectors, a survey of molecular cloning vectors and their uses (ed. R.L. Rodriguez and D.T. Denhardt), pp. 437-456. Butterworths, Boston.

Proudfoot, N.J. and G.G. Brownlee. 1976. 3' Non-coding region sequences in eukaryotic messenger RNA. Nature 263: $211-$ 214.

Riggleman, B., E. Wieschaus, and P. Schedl. 1989. Molecular analysis of the armadillo locus: Uniformly distributed transcripts and a protein with novel internal repeats are associated with a Drosophila segment polarity gene. Genes Dev. 3: $96-113$.

Robertson, H.M., C.R. Preston, R.W. Phillis, D.M. JohnsonSchlitz, W.K. Benz, and W.R. Engels. 1988. A stable genomic source of $\mathrm{P}$ element transposase in Drosophila melanogaster. Genetics 118: 461-470.

Salz, H.K., E.M. Maine, L.N. Keyes, M.E. Samuels, T.W. Clie, and P. Schedl. 1989. The Drosophila female-specific sexdetermination gene, Sex-lethal, has stage-, tissue-, and sex-specific RNAs suggesting multiple modes of regulation. Genes Dev. 3: 708-719.

Sander, K. 1976. Specification of the basic body pattern in insect embryogenesis. Adv. Insect Physiol. 12: 125-238.

Sander, K. and R. Lehmann. 1988. Drosophila nurse cells produce a posterior signal required for embryonic segmentation and polarity. Nature 335: 68-70. 
Sanger, F., S. Nicklen, and A.R. Coulson. 1977. DNA sequencing with chain terminating inhibitors. Proc. Natl. Acad. Sci. 74: 5463-5467.

Schmidt, O., D. Zissler, K. Sander, and K. Kalthoff. 1975. Switch in pattern formation after puncturing the anterior pole of Smittia eggs (Chironomidae, Diptera). Dev. Biol. 46: 216-221.

Schwartz, R.M. and M.O. Dayhoff. 1978. Matrices for detecting distant relationships. In Atlas of protein sequences and structure (ed. M.O. Dayhoff), pp. 353-358. National Biomedical Research Foundation, Washington, D.C.

Seidel, F. 1929. Untersuchungen über das Bildungsprinzip der Keimanlage im Ei der Libelle Platycnemis pennipes I-V. Wilhelm Roux's Arch. Entwicklungsmech. Org. 119: 322440.

Southern, E.M. 1975. Detection of specific sequences among DNA fragments separated by gel electrophoresis. I. Mol. Biol. 98: 503-517.

Spradling, A.C. and G.M. Rubin. 1982. Transposition of cloned $P$ elements into Drosophila germ line chromosomes. Science 218: 341-347.

Staden, R. 1986. The current status and portability of our sequence handling software. (Summary for May 1985). Nucleic Acids Res. 14: 217-231.

Steinert, P.M., A.C. Steven, and D.R. Roop. 1985. The molecular biology of intermediate filaments. Cell 42: 411-419.

Stevens, W.L. 1942. Accuracy of mutation rates. I. Genet. 43: $301-307$.

Steward, R. and C. Nüsslein-Volhard. 1986. The genetics of the dorsal-Bicaudal-D region of Drosophila melanogaster. $G e$ netics 113: 665-678.

Steward, R., F. McNally, and P. Schedl. 1984. Isolation of the dorsal locus of Drosophila. Nature 311: 262-265.

Steward, R., S.B. Zusman, L.H. Huang, and P. Schedl. 1988. The dorsal protein is distributed in a gradient in early Drosophila embryos. Cell 55: 487-495.

Struhl, G. 1989. Differing strategies for organizing anterior and posterior body pattern in Drosophila embryos. Nature 338: $741-744$.

Tautz, D. 1988. Regulation of the Drosophila segmentation gene hunchback by two maternal morphogenetic centers. Nature 322: 281-284

Tautz, D. and C. Pfeifle. 1989. A non radioactive in situ hybridization method for the localization of specific RNAs in Drosophila embryos reveals a translational control of the segmentation gene hunchback. Chromosoma 98: 81-85.

Warrick, H.M. and J.A. Spudich. 1987. Myosin structure and function in cell motility. Annu. Rev. Cell Biol. 3: 379-421.

Yajima, H. 1960. Studies on embryonic determination of the harlequin-fly, Chironomus dorsalis: I. Effects of centrifugation and of its combination with constriction and puncturing. I. Embryol. Exp. Morphol. 8: 198-215.

1964. Studies on embryonic determination of the harlequin-fly, Chironomus dorsalis: II. Effects of partial irradiation of the egg by ultraviolet light. J. Embryol. Exp. Morphol. 12: $89-100$.

Yang, J.T., R.A. Laymon, and L.S.B. Goldstein. 1989. A threedomain structure of kinesin heavy chain revealed by DNA sequence and microtubule binding analyses. Cell 56: 879889. 


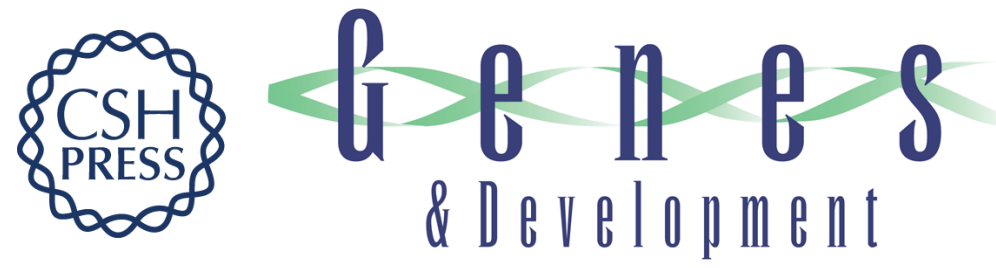

\section{Bicaudal-D, a Drosophila gene involved in developmental asymmetry: localized transcript accumulation in ovaries and sequence similarity to myosin heavy chain tail domains.}

B Suter, L M Romberg and R Steward

Genes Dev. 1989, 3:

Access the most recent version at doi:10.1101/gad.3.12a.1957

References This article cites 63 articles, 15 of which can be accessed free at:

http://genesdev.cshlp.org/content/3/12a/1957.full.html\#ref-list-1

License

Email Alerting

Service

Receive free email alerts when new articles cite this article - sign up in the box at the top right corner of the article or click here.

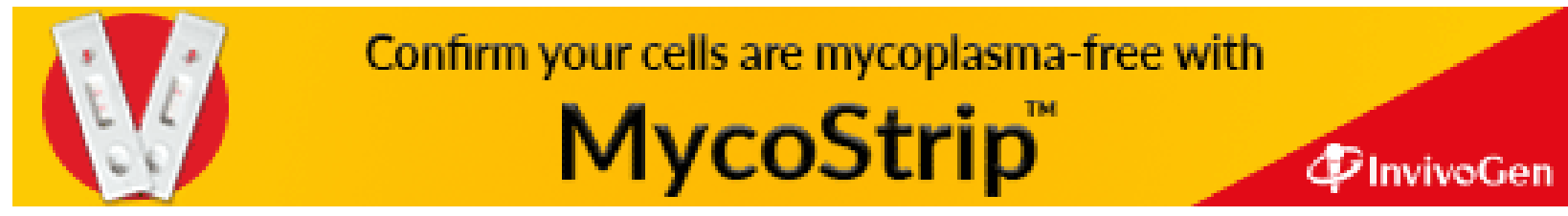

